\title{
A DEMOCRACIA COMO INSTITUCIONALIDADE DA AÇÃO POLÍTICA
}

\author{
DEMOCRACY AS THE INSTITUTIONALITY OF POLITICAL ACTION
}

Rogério Gesta Leal ${ }^{\mathrm{I}}$

I Universidade de Santa Cruz do Sul, Santa Cruz do Sul, RS, Brasil. Doutor em Direito. E-mail: gestaleal@gmail.com
DOI: http://dx.doi.org/10.31512/rdj.v21i41.632

Recebido em: 20.08.2020

Aceito em: 14.02 .2021
Resumo: $\mathrm{O}$ presente estudo tem como escopo analisar a importância das dimensôes institucionais da Democracia, com o intuito de responder o seguinte problema de pesquisa: Em que medida a legitimidade das instituições democráticas são importantes na perspectiva coerencial da Democracia enquanto regime de governo? A hipótese que vamos sustentar aqui é que urge termos compreensão mais ampliada e crítica destas dimensôes institucionais, a ponto de tê-las como condicionadas normativamente a princípios, finalidades e objetivos previamente demarcados nomeadamente pelo ordenamento jurídico constitucional. $\mathrm{O}$ método de abordagem do presente trabalho foi o hipotético-dedutivo, partindo-se de reflexôes sobre o tema alinhadas pela doutrina especializada. A técnica de pesquisa adotada foi a bibliográfica na elaboração do referencial teórico. A justificativa centrase na necessidade de analisar estas dimensóes institucionais diante do complexo cenário imposto pelos modelos democráticos.

Palavras-chave: Democracia. Instituições Democráticas. Regimes de Governo.

Abstract: The present study aims to analyze the importance of the institutional dimensions of Democracy, in order to answer the following research problem: To what extent are the legitimacy of democratic institutions important in the coherent perspective of Democracy as a government regime? The hypothesis that we are going to support here is that there is an urgent need for a broader and more critical understanding of these institutional dimensions, to the point of having them as normatively conditioned to principles, purposes and objectives previously demarcated, namely by the constitutional legal system. The method of approach of the present work was the hypothetical-deductive, starting from reflections on the theme aligned with the specialized doctrine. The research technique adopted was the bibliography in the elaboration of the theoretical framework. The justification is based in the necessity to analyze these institutional dimensions in a complex scenario imposed by democratic systems.

Keywords: Democracy. Democratic Institutions. Government Regimes. 


\section{Notas introdutórias}

Por incrível que possa parecer o debate sobre a necessidade de governos agirem sob os termos da Lei nas Democracias contemporâneas ganha cada vez mais relevo, justamente em face dos fenômenos de corrupçáo, improbidades administrativas e crimes praticados contra o interesse público por todas as partes.

Assim, nos propomos a enfrentar, neste texto, o problema da institucionalidade formal e material da Democracia enquanto regime de governo, e como devemos compreende-la para dar conta de suas formataçóes constitucionais contemporâneas, em especial no Brasil.

Como hipótese, sustentamos que esta institucionalidade passa necessariamente pelo sistema jurídico vigente - constitucional e infraconstitucional -, o qual estabelece inclusive expectativas mínimas que podemos ter dela.

Como metodologia de abordagem vamos utilizar a hipotético-dedutiva, partindo de algumas premissas teóricas no âmbito do tema eleito, para então avançar com proposiçóes contributivas ao enfrentamento dos desafios que ele apresenta. A justificativa centra-se na necessidade de analisar estas dimensóes institucionais diante do complexo cenário imposto pelos modelos democráticos.

\section{Democracia e suas múltiplas expectativas institucionais}

Será que não esperamos muito da Democracia, quando, por exemplo, temos demasiadas expectativas no que tange a participação social na tomada de decisões políticas que afetam as nossas vidas? Ou quando temos a expectativa de que aqueles que respondem pelos debates públicos sobre interesses comunitários e os implementam sejam responsáveis em face dos seus eleitorados?

A verdade é que os democratas todos desejamos - e geramos expectativas em decorrência disto - que a Democracia seja capaz de nos ajudar a fazer um mundo melhor para vivermos pacifica e ordenadamente. Nós acreditamos que isto diminuiria injustiças e opressóes, além do que traria razóes para fundamentar e justificar a organização da vida coletiva, daí porque seguidamente a Democracia é elogiada como capaz de reduzir a probabilidade da guerra, para os mais liberais, protegendo a liberdade e facilitando o crescimento econômico; para os mais socialdemocratas, protegendo a igualdade e o desenvolvimento social sustentável.

Enfim, podemos também afirmar que Democracia é tudo aquilo que todas as pessoas desejam para suas vidas, passível de coexistir com os interesses públicos da comunidade em que coabitam; então é adequado dizermos que há imensa propensão de associarmos Democracia com a ampla variedade de atividades e resultados que as pessoas valoram positivamente para si.

Por tudo isto, é crível que as Democracias causem, historicamente, desapontamentos por quebra de altas expectativas! 
Modo geral, os níveis de participação democrática são fugazes, tornando a accountability mais nominal do que real, evidenciando-se os mecanismos de tomada de decisôes democráticas muito obscuros.

Longe de reduzir injustiças e opressões, situações de pobreza extremas convivem com cenários de riqueza opulenta e concentrada em poucas mãos em muitas Democracias contemporâneas, decorrendo daí que elas se sustentam tanto em discriminaçóes sociais como em razões humanitárias, explicitando complexas e paradoxais inter-relações que sublinham vulnerabilidades sociais agudizadas. $\mathrm{E}$ isto pode ser tomado como patologias passiveis de serem extintas quando estamos tratando de regimes e governos democráticos? A resposta é não! Justamente porque os ideais e expectativas democráticos vivem em permanentes tensôes adaptativas com as realidades políticas quotidianas (LEAL, 2020).

Lembremos que os paradigmas conceituais de Democracia da filosofia e política Moderna no Ocidente centram-se nas premissas da igualdade perante a Lei e dos governos de acordo com esta Lei. E a despeito de que tais paradigmas tenham sido construídos a partir da ideia de Sociedades mais homogêneas e menores, e por isto também foram colocados a prova - e violados - desde então, ainda contam com vigor fundamentalizante.

O problema é que a perspectiva de que seria possível, com o uso da razão moderna e iluminada, constituir altos níveis de objetivos e finalidades comuns entre os cidadãos, por conta de possuírem interesses passiveis de aproximação sobre questôes de vida em Comunidade, não tem se confirmado ao longo do tempo, porque o mundo e as relaçóes humanas não foram se mostrando como simples e passiveis de governança facilitada, mas ao contrário, tem-se revelado como altamente tensas e conflituosas, reclamando medidas de contenção e gestão interventiva para os fins de garantir extratos de civilidade mínimos (DRYZEK, 2000).

E mesmo com mecanismos institucionais de participação política a disposição da Sociedade, esta não os exerce cotidianamente, a não ser em situaçôes limites de crises notadamente econômicas, somadas com altos índices de corrupção, violência e insegurança, mas ainda aqui por meio de movimentos de contestação, denúncia e protestos de massas, com curta duração e baixa densidade propositiva. Isto só aumenta os riscos de abusos de poder e desvios de finalidades por parte dos gestores públicos (GOMÉZ, 2020).

A própria ideia clássica de representação política nesta ordem de argumentos resta empobrecida, na medida em que o tão aclamado princípio democrático da regra das maiorias se vê fragilizado em ambientes sociais e institucionais nos quais a transparência, a prestação de contas dos agentes públicos, os controles internos e externos da Administração Pública, não se operam com a devida adequação e eficiência. Neste ponto Adam Przeworski lembra que a Democracia como vontade de maiorias, uma vez desacompanhada de participação social efetiva - além de funcionamento democrático das instituiçóes representativas -, revela-se como regime pobre para os fins a que se pretende (PRZEWORSKI, 2011). 
Nos dias atuais, marcados por conflitos de interesses endêmicos das mais diversas naturezas, os valores democráticos derivam não tanto de promessas de redistribuição, mas mais da possibilidade de gestar tais conflitos de forma pacifica - de certa forma premissa presente no trabalho de Schumpeter (2003), o que amplia alguns conceitos mais clássicos da ação política democrática, não só porque resgata a ideia da vontade geral rousseauniana (e suas declinaçóes mais vinculadas à democracia de massas), mas também porque desvincula a legitimidade democrática de pretensão absoluta de que os políticos representam seus votantes de forma absoluta e permanente.

Esta perspectiva da competição democrática - a despeito de suas fragilidades matriciais voltadas ao frágil reconhecimento das dificuldades de isonomia entre os competidores, notadamente econômicas e de articulação política - nos faz reconhecer, ao menos faticamente e nos dias atuais, que tem se operado desvirtuamentos muito fortes desta dimensão competitiva da democracia, basta olharmos para os processos eleitorais em muitos países em todo o mundo, quando verificamos a política ser vendida como produto (sufrágio enquanto mercancia); produto este formatado não em processos de debates públicos legítimos e participativos, mas construído a partir de técnicas de propaganda e publicidade que visam seduzir o comprador/eleitor a adquirir promessas e sonhos bem apresentados e persuasivos em níveis de cognição crítica muito deficitários.

O que importa nestes cenários não são valores, objetivos e finalidades humanitárias e inclusivas a serem discutidas e perseguidas por políticas públicas, mas que a competição pelo poder e através dele está institucionalizada, razão pela qual os perdedores de determinada eleição devem aceitar seus fracassos em troca da segurança e paz que a ordem estabelecida garante, em face da perspectiva/possibilidade de, no próximo pleito, usando das mesmas táticas e estratégicas, vencerem a eleição.

A despeito disto, mesmo nas experiências socialistas mais radicais da história contemporânea vimos ocorrer desvios de projetos originariamente emancipatórios e igualitários com o detrimento da participação política e social nas deliberações públicas importantes, assim como a constituição de modelos de capitalismo de Estado, centralizado institucional e politicamente.

Por tais razóes é que Giorgio Agamben já teve oportunidade de dizer que:

The term democracy sounds a false note whenever it crops up in debate these days because of a preliminary ambiguity that condemns anyone who uses it to miscommunication. Of what do we speak when we speak of democracy? What is the underlying rationale? An alert observer will soon realize that, whenever she hears the word, it might mean one of two different things: a way of constituting the body politic (in which case we are talking about public law), or a technique of governing (in which case our horizon is that of administrative practice). To put it another way, democracy designates both the form through which power is legitimated and the manner in which it is exercised (AGAMBEN, 2009, p. 04). 
O autor também lembra que estes dois aspectos e áreas da Democracia - jurídico-política e econômica-gerencial - têm se justapostos ao longo do tempo desde o nascimento da política no Ocidente, assim como do pensamento político (na própria democracia grega e suas cidadesestados), o que torna difícil separá-los de forma abrupta.

Normas jurídicas regulam as açóes de governo pelo simples fato de que, a partir do constitucionalismo moderno, este somente pode agir de acordo com o que aquelas permitem, e isto se deu por conta de muitas variáveis políticas, econômicas e também filosóficas que vamos abordar neste texto.

A relação que há entre normas jurídicas e ações governamentais, pois, dizem com obrigaçóes, obediências a compromissos, finalidades e objetivos previamente traçados pelos sistemas jurídicos (constitucional e infraconstitucionais) vigentes, e mais que isto, evidencia escolhas estratégicas tomadas por procedimentos e processos legitimamente democráticos envolvendo múltiplos protagonistas do espaço público e privado, o que reforça os vínculos não facultativos em termos de efetivação de deveres e direitos.

O problema é quando, no Estado de Direito, em especial na Administração Pública, o sistema jurídico é utilizado para perseguir fins mais privados do que públicos, o que revela desequilíbrios tanto na distribuição de poder como em seu exercício, permitindo que grupos sociais mais fortes de que outros assaltem o governo/Estado para efetivar projetos e metas descompromissadas com os interesses da Comunidade como um todo. Em tais circunstâncias, surge tensóes entre maiorias e minorias que devem ser equacionadas de maneira a reestabelecer aqueles equilíbrios ameaçados ou violados.

De qualquer sorte o velho problema moral sobre o porquê as pessoas obedecem às leis, e com que motivaçóes, volta sempre à mesa quando se debate a funçáo dos sistemas normativos nos dias atuais. A despeito disto, de acordo com o que podemos chamar de formulaçáo conceitual standard, as leis devem possuir certas características universais, devendo ser: gerais, promulgadas publicamente, náo retroativas (como regra), claras e compreensíveis, consistentes sob o ponto de vista lógico, factíveis e estáveis ao longo do tempo (FULLER, 1964).

Em face destes elementos e numa concepção normativa forte, a lei - notadamente a constitucional - é fonte de sua própria normatividade, ou seja, se normas se qualificam como leis, então é obrigação de agentes públicos e privados seguirem o que elas determinam, mesmo que as motivaçóes para o agir destes sujeitos de direito não sejam de cunho moral (MARAVALL; PRZEWORSKI, 2003). Por isto a assertiva de que, independentemente da motivação para a observância do disposto em normas jurídicas, o mais valioso efeito do Estado de Direito é que ele possibilita a autonomia individual no âmbito das relaçôes humanas e institucionais, observados os parâmetros jurídicos estabelecidos para este exercício.

Esta perspectiva está ancorada na ideia Moderna de que as dimensóes políticas e jurídicas dos atos de governo devem estar associadas aos termos do contrato social que as instituiu, sendo este fundado também nas concepçôes modernas de vontade geral e soberania popular. E aqui 
temos pontos de contato entre o pensamento de Aristóteles e de Rousseau, a saber: As with Aristoteles, sovereignty, that which is kyrion or supreme, is at the same time one of the two terms being distinguished, and the indissoluble link between constitution and government (AGAMBEN, 2009, p. 06).

Por outro lado, as açóes de governo que são - em parte - previsíveis sob o ponto de vista da normatividade que as autoriza e as estabiliza no tempo, são também limitadas pelas condiçóes da autonomia individual decorrente do reconhecimento normativo do mesmo Estado de Direito. Desta maneira, para podermos compreender melhor este Estado - e o sistema jurídico que o informa - devemos levar em conta as forças políticas que vão constituir aqueles comandos, os objetivos que veiculam, assim como os conflitos - aparentes e ocultos - próprios destes cenários, pois, para avançar em seus objetivos, os atores dos espaços públicos e privados sempre lançam mão de instrumentos (econômicos, militares, ideológicos) de que possam dispor (por vezes nem todos lícitos).

O Estado, então, é um sistema de instituições que possui, cada qual, prerrogativas, objetivos e funçóes normativamente estabelecidos, com as quais se vinculam sempre, e por eles podem ser controlados - interna e externamente. Assim sendo, é possível afirmarmos que estes configuram a verdadeira fonte institucional de poder do Estado de Direito. O problema é que estas fontes de poder, por sua vez, são constituídas no (e são o resultado do) embate de interesses públicos e privados, mesmo que respeitando o devido processo legal para tanto, o que coloca o risco de que eventuais distribuiçóes e exercício desajustados de poder entre os atores que participam destes processos deem causa a distorçóes que envolvam exclusóes sociais impactantes, inclusive resultando na violação de Direitos Fundamentais (HAMPTON, 1999).

Por isto, se grupos organizados e hegemônicos de poder (econômico e político) náo podem usar as leis para seus interesses exclusivos, eles terão de se valer dos mecanismos institucionais e de direito que existem para tanto - os quais, em tese, se constituem e deveriam funcionar a partir de determinados equilíbrios sociais-, o que traz para a arena pública e mais controlada os embates de projetos privados/corporativos e sociais, oportunizando maior visibilidade e transparência a todos. Daí a correta expressão de Maravall \& Przweorski (2003, p. 05): The difference between rule by law and rule of law lies then in the distribution of power, the dispersion of material resources, the multiplication of organized interests; in societies that approximate the rule of law, no group becomes so strong as to dominate the others, and law, rather than reflect the interests of a single group, is used by the many.

Em outras palavras, o plano da institucionalidade normativa que regula açóes individuais e institucionais cria ambientes de segurança e confiança dos protagonistas da política, economia e governo, assim como gera expectativas passiveis de serem cumpridas pelas pessoas (físicas e jurídicas), aumentando os níveis de estabilidade das relaçôes. Então podemos afirmar que instituiçôes orientam, por vezes, açóes, justamente porque elas - em alguns cenários - podem 
constituir incentivos e expectativas, e o próprio conjunto destas iniciativas podem induzir forças políticas a portarem-se de acordo com diretrizes institucionais.

Mas tudo isto só pode acontecer se efetivamente existirem bases institucionais claras e consistentes para o funcionamento de regimes democráticos e para o exercício do poder político! Lembremos somente do caso chileno, quando o general Pinochet, em outubro de 1989, poucas semanas antes das primeiras eleiçôes democráticas, depois do referendo de 1988, advertira em alto som que se a novel Democracia tocasse em algum de seus homes, o Estado de Direito voltaria a se extinguir (O’DONNELL, 1999). Neste exemplo resta claro que a existência do Estado de Direito depende da vontade de uma pessoa - respaldada por muito setores hegemônicos -, o que fragiliza de forma letal as dimensôes institucionais que deveriam constituir e manter a ordem democrática.

Por outro lado, seguidamente afirma-se que o importante é instituirmos o governo das leis e não de homens, expressão esta demasiadamente ambígua, simplesmente porque os atos de governo não podem ser reduzidos as expressóes gramaticais das normas jurídicas vigentes. Ao mesmo tempo tal assertiva significa que os governantes estão vinculados ao que determinam as leis e, portanto, o governo operado por homens deve cumprir estas normas. Da mesma maneira as expressóes soberania e supremacia da lei não podem induzir que os elementos subjetivos e interpessoais dos atos de governo possam estar blindados de forma absoluta por tais premissas! Vale a advertência de Agamben:

To think of government as simple executive power is a mistake and one of the most consequential errors ever made in the history of Western politics. It explains why modern political thought wanders off into empty abstractions like law, the general will, and popular sovereignty while entirely failing to address the central question of government and its articulation, as Rousseau would say, to the sovereign or locus of sovereignty (AGAMBEN, 2003, p. 07).

Ao contrário, as leis, enquanto criações humanas, estão sujeitas sempre a determinadas intençóes e desejos privados que se mesclam (as vezes de forma ilícita) com os públicos, o que se evidencia, por exemplo, nos índices e casos de corrupçáo governamental em todo o mundo. Dai porque, como lembra Jon Elster, as leis não podem estar acima dos homens porque nada é externo à Sociedade, sendo possível inúmeras circunstâncias nas quais as leis podem ser ignoradas, desconsideradas, violadas ou suspensas (ELSTER, 2011).

A ideia/premissa central que está por detrás do Estado de Direito, portanto, é a da universal observância das regras que definem o sistema político e regulam seu funcionamento, os quais apontam, sempre, para o cumprimento a máxima potência de direitos e garantias sociais e individuais consagrados constitucional e infraconstitucionalmente. Se nada é externo a Sociedade, a Sociedade que é bem ordenada em termos institucionais é aquela na qual as regras de direito são de tal forma consideradas pelos cidadãos que ninguém encontra vantagens para agir contrário a elas. Mas esta é uma ideia regulativa (ou tipo ideal), i.é, constitutiva das condiçôes e possibilidades da própria Democracia e Estado de Direito enquanto conquista civilizatória, mas não nega que os riscos e perigos de violação destas premissas são constantes nos 
múltiplos espaços e tempos das relaçôes sociais e institucionais contemporâneas, nomeadamente em relaçóes de Mercados capitalistas.

Em verdade, as relaçóes entre Democracia e Mercado nunca foram as mais pacíficas e equilibradas, justamente porque o segundo tem em sua genética constitutiva e evolver histórico, muitas vezes, ações e reaçôes detratoras daqueles direitos, pois decorrência das premissas relacionadas com lucro a qualquer preço e o crescimento econômico não necessariamente associado com o desenvolvimento social sustentável. E tais elementos são convulsivos, fazendo até questionar, em certa medida, o (in)sucesso dos regimes democráticos para fazer valer as promessas de igualdade em vida digna para todos. Em tais cenários ganha força o argumento de Roemer no sentido de que, dependendo dos níveis de desigualdade social, tấo importante, ou mais, nas Democracias, do que evitar injustiças, é reduzi-las a patamares mais civilizados, progressiva e continuamente (ROEMER, 1996).

O problema é que existem muitos obstáculos para que as Democracias levem a cabo o tema da redistribuição das condiçôes dignas de vida e os meios para consegui-la. Roemer (1996) lembra que naqueles países em que há altos níveis de acordos axiológicos relacionados a politicas distributivas, como nos Estados Nórdicos, as pressóes sobre os regimes democráticos para ampliá-las são menores, mas quando as políticas são multidimensionais, no âmbito das percepçóes da esquerda e direita no que diz respeito a preocupaçóes distributivas, conectadas ainda a compreensôes autoritárias ou liberais referentes aqueles acordos, como nos EUA, tais pressôes são cada vez maiores e tópicas.

Por tais percepçóes é que ganha relevo o tema da institucionalidade governativa, eis que:

One of the main characteristics of institutions is that they are impersonal, in the sense that their functioning does not depend on the idiosyncrasy of individuals. An institution is well designed when it is not affected by the replacement of the individuals who have to act in accord with its rules. Whatever the preferences of individuals who have to act institutionally, the institution survives when the incentives it creates induce individuals to comply with the rules. In this sense, there is rule of law when politics is fully institutional, that is, when every political act is done according to the institutional rules. The challenge posed by the rule of law is the design of a set of rules that guarantee their own survival because the incentives contained in these rules deter everyone from subversion (CUENCA, 2003, p. 63).

Estes aspectos são essenciais para qualquer regime democrático, e a nosso juízo indispensáveis para ultrapassarmos certas culturas patrimonialistas e paternalistas de atores políticos e modos de governança. Não que isto nos garanta estabilidades institucionais eternas, mas ao menos representaçóes mais claras e passiveis de controles públicos eficientes, sempre tendo em conta que imprevisíveis mudanças sociais, decorrentes de forças políticas e econômicas distintas, transformam a todo o instante o equilíbrio entre os poderes e entre as instituiçóes (públicas e privadas), por vezes destruindo modelos antigos e criando novos.

Então poderíamos perguntar: qual o objetivo da estabilidade institucional? Por que ela é tão importante? E tais interrogantes trazem outros ainda mais gerais: Por que o respeito e 
compromisso as leis é tão importante? O que ocorre se estas normas são subvertidas, fazendo com que o sistema não seja estável?

E uma das primeiras respostas de fundo que surge a tais questionamentos é a de que $o$ compromisso e observância as regras democráticas (e jurídicas) postas as relações sociais poderiam ser explicadas a partir do fato de que elas refletem a distribuição dos poderes de barganhas entre os diferentes segmentos sociais representados no espaço público. Ou seja, se o exercício do poder sob determinadas normas públicas vinculantes coincide com as expectativas e demandas de forças sociais relevantes/hegemônicas conjunturalmente, inexistirão incentivos eficientes e suficientes para que aquelas normas sejam rompidas. Por óbvio que isto desloca (e aqui temos um problema) - sob o ponto de vista filosófico - o fundamento de validade fática dos sistemas normativos vigentes do argumento da sua legitimidade axiológica e deontológica para o de sua sustentação pragmática social, política e econômica, o que se revela muito mais fugaz e instável - mas é assim mesmo que ocorre no mundo da vida (CALVERT, 2015).

Há quem diga que este argumento é insustentável nos dias atuais, porque ele ignora o fato de que algumas normas institucionais simplesmente criam novos espaços e protagonistas de poder, os quais não podem ser facilmente reduzidos aos âmbitos de barganhas pré-institucionais.

Vejamos o exemplo, no Brasil, da criação na ordem constitucional de 1988 dos chamados Conselhos federais, estaduais e municipais, com escopo de ampliar a participação popular na gestão pública, gerando a formatação institucional de milhares destes espaços institucionais em todo o pais, todavia, muitos deles, por artimanhas e arranjos absolutamente corporativos de segmentos sociais mais poderosos, foram constituídos por atores demasiadamente comprometidos com suas corporaçôes, e não com o interesse público, esvaziando as funçôes matriciais que lhes deram vida.

O Estado de Direito está constituído, fundamentalmente, pelo princípio de que toda a ação política tem consequências no que diz com o tema da distribuição do poder institucional pela via do sistema jurídico, razão pela qual não se pode aceita-la alicerçada sobre o exercício da força bruta - que deve ser domada pela força institucional. Ou seja, na medida em que todos sabem - por regras claras, públicas e universais - quem está autorizado a fazer algo em termos de política institucional e de acordo com que procedimentos específicos, tudo baseado na Lei, os sistemas institucionais constituem-se e mantém-se estáveis, e o respeito a eles existe e é garantido por instrumentos de responsabilização adequados, o que gera nos indivíduos expectativas confiáveis em termos de açóes e reaçôes governamentais e sociais no quotidiano de suas vidas, fortalecendo a Democracia e suas instâncias operacionais.

O problema é que a constituição política de regras de comportamento, seja governamental, de mercado ou individual, nem sempre garante que tais ações se deem respeitando integralmente aqueles comandos, isto porque algumas açóes políticas decorrentes destas regras podem ter como escopo - e gerar consequências - não institucionais, o que evidencia ser o compromisso a elas, por vezes, problemático. Isto nos leva a conclusão de que a constitutividade destas regras, ao menos 
no campo da política, é uma questão de grau, cambiante em face de variáveis não controladas institucionalmente (econômicas, culturais, religiosas, etc.), o que representa certo risco de colapso do sistema - nomeadamente porque coloca em risco a confiança de todos os envolvidos/ alcançados nas expectativas prometidas.

Agora, temos de atentar para o fato de que o Estado de Direito não pode ser reduzido - e para alguns sequer pode representar (FINNIS, 1980) - a um regime de governo. Mesmo que a fórmula governo de leis e não de homens possa nos sugerir a possibilidade da nomocracia (enquanto ordem político-jurídica de sociedade pluralista, sem hierarquia comum de fins particulares (HAYEK, 1967), isto trata tão somente de possibilidade metafisica desprovida, de qualquer significado político empírico substancial.

Tampouco pode o Estado de Direito ser resumido na articulação jurídica da política, porque não podemos confundir sistemas políticos que usam instrumentos legais para o exercício do poder, sem considerar a legitimidade, o conteúdo e a forma procedimental deste exercício, com o Estado de Direito de que estamos falando, haja vista, inclusive, a advertência de Carl Schmitt no sentido de que governar por intermédio da Lei pode não ser o mesmo que governar de acordo com a Lei (SCHMITT, 1970). Ou seja, muitos governos, inclusive eleitos democraticamente, podem tornar-se totalitários, lançando mão de legislaçôes tirânicas para tentar legitimar seus atos despóticos.

$\mathrm{O}$ que coloca em cheque alguns dos argumentos liberais mais contemporâneos, como os de Robert Dahl, quando considera as vantagens do sistema político poliarquico, pois nele os governantes são selecionados através de eleiçôes livres garantidas sobre a base de determinadas regras por todos conhecidas, e em ambientes nos quais suas condiçôes estão postas e também asseguradas (como liberdade de associação, de expressão, etc.), e isto seria o fundamental para que a Democracia (ideal) pudesse se desenvolver. E por que isto não é suficiente? Porque Dahl assim como tantos outros liberais - parte da equivocada premissa de que o Estado de Direito e a Democracia passam a existir tão somente quando tais regras são respeitadas e suas leis satisfaçam condições mínimas de constituição! Isto não é o suficiente, haja vista que as próprias regras (e governos) democráticas, por vezes, possuem âmbitos de ambiguidade e vagueza (muitas vezes propositais), e nestes espaços de incertezas normativas comportamentos individuais e sociais vão deturpando/defraudando o sistema criado sob a perspectiva dos Direitos e Garantias Fundamentais. Daí a importância da mobilidade permanente da Sociedade para vigiar, controlar e responsabilizar governos e democracias (DAHL, 1971).

De qualquer sorte, podemos concordar que o princípio básico do Estado de Direito é que os atos das autoridades instituídas formalmente - nomeadamente dos agentes públicos -, relacionados com os interesses públicos vinculantes existentes, devem estar sempre legitimados pelos termos trazidos pelo sistema jurídico vigente. Por isto Ignacio Cuenca propóe: the rule of law as compliance with the law, when the law is general, public, prospective, clear, consistent, performable, and stable. This definition includes under the problem of compliance both interference 
with the basic rights of individuals and obedience to the rules that establish who has the authority to rule and how this authority is to be exercised (CUENCA, 2003:69).

Atentemos para o fato de que o elemento que diferencia o sentido forte do sentido fraco de Estado de Direito é a distinção entre obedecer à lei e estar sujeito a ela (ser constrangido por ela). A ideia de obedecer à lei não pressupóem nada, em nível pragmático, relacionado as razóes que justificam e fundamentam a sua submissão, pois alguém pode obedecer à lei simplesmente porque ela está conforme os seus interesses e desejos, e não por conta dos bens jurídicos que ela protege e regula. Daí porque estar sujeito a lei diz mais com demandas maiores, na medida em que os próprios legisladores têm restriçôes (constitucionais e infraconstitucionais) que limitam suas capacidades de alterar/criar a Lei.

O sentido fraco do Estado de Direito nada tem a dizer sobre mudanças normativas, podendo ser chamado de estático porque não faz qualquer suposição sobre as normas jurídicas, enquanto que o seu sentido forte é dinâmico, na medida em que assume que os legisladores devem enfrentar, de diferentes formas e intensidades, restriçóes no que tange a mudanças normativas. Assim, questôes sobre a viabilidade do Estado de Direito evidenciam-se como verdadeiramente interessantes quando envolvem estas perspectivas do sentido forte e dinâmico, pois aqui estaremos diante de elementos neurais da observância da norma e de sua legitimidade conformativa.

A verdade é que o Estado de Direito reclama observância as normas jurídicas vigentes - constituídas ou náo legitimamente; ou seja, a premissa fundante deste Estado é a de que tais normas sejam sempre respeitadas por todos. Isto implica que o sistema político está, de certa forma, fechado ou autocontido, no sentido de que não pode recorrer a fontes extralegais para resolver problemas ou desencadear políticas públicas. Quando a revolução, a guerra, ou qualquer outro ato (individual ou social) destrói este sistema, nomeadamente quando conflitos não são solvidos conforme as normas, é o próprio Estado de Direito que se fragiliza e esmorece. Neste ponto nos diz Ferejohn e Pasquino:

What is often meant by rule of law is no more than the notion that government should work its will through general legislation, legislation to which the governors themselves are subject, rather than through irregular decrees and ad hominem proclamations. But rule of law may require more than this: it may require that people are able to foresee accurately the legal consequences of their actions and not be subject to sudden surprises whether or not these take the form of legislation, or perhaps that the law contain, or at least not violate, certain substantive principles and rights (FEREJOHN; PASQUINO, 2003, p. 242).

E isto se dá porque o sistema jurídico é o instrumento básico da vida em Sociedade, constituindo a mais importante invenção técnica no campo da política, e é graças a ele que podemos criar e contar com instituiçôes representativas de demandas e expectativas confiáveis à gestão de interesses e bens tão distintos da vida quotidiana, públicos e privados.

Mas nem todas as regras são de permissão ou de proibição! Lembrando novamente Searle, devemos distinguir entre normas regulativas e constitutivas, sendo as primeiras destinadas 
a regulação de experiências que independem de normas prévias, pois até podem existir antes de que tais normas tenham sido introduzidas em Sociedade (estamos falando aqui de procedimentos administrativos, por exemplo, que vão criar rotinas, métodos de consecução operacional de objetivos e fins os mais diversos); já as normas constitutivas fazem possíveis certas atividades que não poderiam se dar sem sua existência (licitaçóes públicas não poderiam se dar sem prévias disposiçôes sobre como deveriam ocorrer e o que visam enquanto bem jurídico tutelável) (SEARLE, 1999).

As razóes pelas quais normas constitutivas de natureza política são diferentes de outras realçam as razóes urgentes de lançarmos luzes aclaradoras sobre as primeiras, pois isto é fundamental para aprofundarmos nossa compreensão sobre o Estado de Direito. Aquelas normas se assemelham as alegorias que Searle faz com o tema das regras linguísticas que formatam determinados jogos, e que estabelecem as condiçóes de possibilidades para suas dimensóes operacionais, exigindo dos jogadores o respeito integral a elas, sob pena de serem excluídos do jogo. Mas para que isto se dê também se faz necessário que os sujeitos linguísticos que desejam constituir operaçôes de comunicação pactuem códigos sintáticos e semânticos passiveis de gerar atos de cognição, compreensão e entendimento recíprocos.

É claro que a política envolve diversas formas de complexidades e tensionamentos distintos de jogos e linguagens, como nos adverte Schauer:

What holds for games or languages is not necessarily true of politics. First, unlike with languages, a unilateral deviation may make sense. The president of a republic may decide to break unilaterally the constitutional rule that establishes a limit on the number of presidential mandates. Second, unlike with games, playing politics is not optional. In most cases there is no outside option. If a person does not like the rules of politics, he cannot decide to abandon the political game. Either he complies with the rules or he breaks them (assuming he does not have enough power to change them). Sometimes, there is an exit option and the person can leave the country. However, this is not always feasible and tends to be costly (SCHAUER, 2011, p. 73).

Estas possibilidades de cenários políticos na Democracia contemporânea se configuram de difícil concreção, pois teriam de suplantar várias barreiras de licitude e factibilidade social, razão pela qual as regras da política e do Estado de Direito possuem caracteres menos propícios a rupturas. De outro lado, a força da lei não é exclusiva ou mesmo fundamentalmente normativa, eis que cidadãos e agentes públicos não obedecem a lei em face tão somente do dever de fazê-lo (por conta de suas consciências críticas de agir de acordo com a lei), mas porque têm incentivos para tanto - como o de não serem responsabilizados juridicamente por comportamentos ilícitos.

É muito comum historicamente termos noçóes abertas e plurissignificativas de Democracia, e talvez, como queira Wendy Brown: Perhaps democracy's current popularity depends on the openness and even vacuity of its meaning and practice-like Barack Obama, it is an empty signifier to which any and all can attach their dreams and hopes (BROWN, 2009, p. 44). Mas tais percepçôes não podem restar permanentemente abertas, ou mesmo admitir sentidos e 
perspectivas divorciadas de determinados parâmetros normativos vinculantes que, no caso, são também constitucionais e infraconstitucionais.

Por outro lado, de certo modo, o que se apresenta como recorrente é o modelo capitalista de Democracia, que opera muito mais sob os fundamentos de direitos liberais individuais do que sociais, dando relevo desmesurado a projetos de vida segmentados econômica, política e ideologicamente, os quais por vezes implicam níveis de exclusão social significativos.

Também a ideia de Democracia, pelo que vimos até aqui, traz em si reivindicação política no sentido de que o povo eleja - a partir de algumas premissas já consolidadas, como as demarcadas pela norma constitucional - o modo de vida que pretende para si, sempre considerando o necessário reconhecimento do outro como alguém que possui legitimas pretensóes existenciais como as suas. Por tais razôes, a Democracia se configura como projeto de vida inacabado, e sua forma constitucional ainda especifica que poderes devem ser compartidos com a soberania popular; como as relaçóes (normativas) devem ser organizadas; quais as instituições ou condiçôes suplementares devem ser consideradas aptas ou seguras para tais intentos.

Estas questões todas vão sendo definidas em processos e sinergias políticas, econômicas, culturais e institucionais as mais diversas, algumas inclusive com marcas duras de enfrentamentos e tensôes tópicas, movidas por interesses e expectativas inconciliáveis, como a da especulação de capitais por instituiçôes financeiras que se vê alimentada por políticas de juros e inflação insuportáveis a população, mas que enriquece cada vez mais um menor numero de pessoas físicas e jurídicas.

\section{Conclusáo}

Toda e qualquer instituição somente pode ser duradoura se contar com incentivos que honrem, respeitem e cotidianamente concretizem seus escopos, daí que a Democracia sobrevive somente se os gestores públicos, Mercado e Sociedade, tenham incentivos para honrar com seus compromissos institucionais (respeito aos direitos e garantias fundamentais, aos preceitos da boa administração pública, aos processos eleitorais e de representação política, a independência do Poder Judiciário e suas decisôes), assim como desincentivos para violá-los (NORTH, 1989).

Somente quando a cidadania, os gestores públicos e os agentes de mercado se comprometem a cooperar e policiar o cumprimento das regras do jogo democrático é que se criam espaços de fomento para o desenvolvimento de relaçôes mais democráticas. Quando existe esta cooperação e monitoramento, surgem mecanismos de ação e reação para os atos de governo e de Estado, aumentando os níveis de respeito e segurança de direitos e garantias.

Claro que temos de levar em conta a existência de interesses privados conflitantes ocupando o espaço público, e mesmo distintas e lícitas demandas sociais e individuais que colocam campos de divergências a serem solvidos a partir de formas e fórmulas de equilíbrios democráticos por vezes tensos e conjunturais. Nestas ambiências, por vezes, restam difíceis as escolhas públicas a 
serem tomadas, pois podem apresentar à decisão pretensôes de legitimidade com semelhantes fundamentos de validade, obrigando o gestor a constituir critérios muito mais contingenciais do que definitivos a solução. Daí a importância de serem criados - com procedimentos claros e efetivamente participativos - critérios/regras públicas de mediação e gestão de todos os interesses individuais e sociais envolvidos em qualquer demanda comunitária.

O problema é que contemplamos hoje certa preponderância de interesses econômicos privados assaltando os Estados e governos, em detrimento da soberania popular e suas demandas de inclusão social e vida digna.

Ao lado disto há sempre o risco de que regimes de governo populistas dificultem a emancipação e participação da cidadania na gestão dos interesses públicos, principalmente aqueles que operam com a lógica de que a Constituição tem de promover o autogoverno e fortificar as vontades das maiorias. Em termos de organização das relaçóes de poder, estes modelos de gestão são caracterizados pela hegemonia do Poder Executivo em detrimento do Legislativo, forjando relaçôes de troca e benefícios com aliados e a própria população, para os fins de manter os níveis de adesão inconsciente a projetos de governo que interessam mais a algumas pessoas vinculadas a interesses econômicos importantes. Dai porque se tem afirmado que:

First, the system of checks and balances may be deemed as the liberal response to both the conservative and the populist conception about the organization of power. Whereas these two alternatives allowed the use of arbitrary powers, the liberals proposed the adoption of a strict system of controls over power. Second, the liberal commitment to a strong idea of individual rights may be deemed as a response to the disregard of minority rights that, the liberals assumed, characterized both the conservative and the populist constitutional views (PZEWORSKI; STROKES, 2012, p. 43).

Por outro lado, podemos dizer também que tanto liberais como radicais de esquerda têm discursos aproximados e negativos sobre abusos e desvios de poder, sustentando que cada manifestação destes poderes - públicos e privados - mantenham-se nos limites da lei; e em especial para os primeiros, garantam a proteçáo de direitos individuais. A despeito de ambos temerem/ combaterem os abusos do poder, os liberais muito particularmente temem em demasia o que chamam de incessante e muito perigosa expansão do Poder Legislativo sobre os demais poderes - legislative encroachments -, enquanto que os segundos temem mais as graduais separaçóes entre o povo/cidadania e seus representantes - political alienation -, e o consequente uso das posiçóes públicas para propósitos privados.

De qualquer sorte, como seguem nos chamando atenção Ferejohn e Pasquino: We expect, for example, or hope, that our government can correct inequities arising from markets or social interactions. Such interventions can involve confiscatory taxes or draconian regulations, either of which can threaten claims for minority rights (Ferejohn; Pasquino, 2003). E este é o custo da Democracia quando opera com base em princípios e compromissada com os parâmetros constitucionais estabelecidos em cada momento histórico, ora defendendo direitos e garantias 
sociais, ora assegurando o exercício de prerrogativas e conquistas dos direitos individuais, formatando equilíbrios sempre tensos e movediços.

O mediador final destes ambientes será o Poder Judiciário - enquanto institucionalidade democrática - e, como fiel da balança, deverá tomar cuidados para que não agregue aquelas equaçóes outros elementos de distorçôes ou desequilíbrios ameaçadores a soberania popular e suas representaçóes políticas.

\section{Referências}

ABRUCIO, Fernando L.; COSTA, Valeriano. M. F. Reforma do Estado e o contexto federativo brasileiro. São Paulo: Fundação Konrad-Adenauer, n. 12, 1998.

ABRUCIO, Fernando L.; COUTO, Carlos. A. Redefinição do papel do Estado no âmbito local. In: Fundação Seade. São Paulo em Perspectiva, v. 10, n 3, jul-set, 1996.

ABRUCIO, Fernando L.; Os Baróes da Federação: os governadores e a redemocratização brasileira. Hucitec/USP. São Paulo, 1998.

ACKERMAN, Bruce \& AYRES, Ian. Voting with Dollars. Yale University Press, 2002.

AGAMBEN, Giorgio. Introductory note on the concept of Democracy. In AGAMBEN, Giorgio (and others edit.) Democracy in what State? New York: Columbia University Press, 2009.

CALVERT, Randall. Rational Actors, Equilibrium and Social Institutions. In BANKS, Jeffrey S. and HANUSHEK, Eric A. (eds.). Modern Political Economy. Cambridge: Cambridge University Press, 2015.

CHIPMAN, Nathaniel. Principles of Government: a treatise on free institutions. Burlington: Gale, Making of Modern Law, 2010.

CILLINS, Mike. The big bank bailout. (2015). Disponível em: https://www.forbes.com/sites/ mikecollins/2015/07/14/the-big-bank-bailout/\#547f7efa2d83. Acesso em 25 nov. 2019.

DAHL, Robert A. Polyarchy. New Haven: Yale University Press, 1971.

DRYZEK, John S. Deliberative Democracy and Beyond - liberals, critics, contestations. New York: Oxford University Press, 2000.

ELSTER, Jon. Making Sense of Marx. Cambridge: Cambridge University Press, 2011.

FINNIS, John. Natural Law and Natural Rights. Oxford: Clarendon Press, 1980.

FULLER, Lon. The Morality of Law. New Haven: Yale University Press, 1964. 
GARGARELLA, Roberto. The majoritarian reading of the rule of law. In MARAVALL, José María e PRZEWORSKI, Adam. Democracy and de Rule of Law. Cambridge: Cambridge University Press, 2003.

GÓMEZ, Julio Alguacil. Nuevos movimientos sociales: nuevas perspectivas, nuevas experiencias, nuevos desafios. In Revista Latinoamericana Polis, n⿳07, Centro de Investigación Sociedad y Politicas Publicas, septiembre de 2007.

GREGG, Benjamin. Using legal rules in an indeterminate world. In Political Theory Review, no27, 3: pp.357-78, 1999.

HAMPTON, Jean. Democracy and the Rule of Law. In SHAPIRO, Ian (ed.). The Rule of Law. New York: New York University Press, 1999.

HAYEK, Friedrich A. The Constitution of Liberty. Chicago: University of Chicago, 1970.

HAYEK, Friedrich A. The principles of a liberal social order. In Studies in Philosophy, Politics and Economics. London: Routledge, 1967.

HOLZ, Hans Heinz. The downfall and future of Socialism. Minneapolis: Minnesota University Press, 1992.

KETCHUM, Ralph (ed.). The Anti-Federalist Papers and the Constitutional Convention Debates. New York: Mentor, 1986.

KNIGHT, Jack. Institutions and Social Conflict. Cambridge: Cambridge University Press, 2002.

LEAL, Rogerio Gesta. Déficits democráticos na Sociedade de Risco e (des)caminhos nos protagonismos institucionais no Brasil. São Paulo: Tirant de lo Blanch, 2020.

LEAL, Rogério Gesta. Estado, Administração Pública e Sociedade: novos paradigmas. Porto Alegre: Livraria do Advogado, 2002.

MANIN, Bernard. Checks, Balances and Boundaries: The Separation of Powers in the Constitutional Debate of 1787. In FONTANA, Biancamaria (ed.). The Invention of the Modern Republic. Cambridge: Cambridge University Press, 1994.

MARAVALL, José María e PRZEWORSKI, Adam. Democracy and de Rule of Law. Cambridge: Cambridge University Press, 2003.

NORTH, Douglas, \& WEINGAST, Barry. Constitutions and Commitment: the evolution of institutions governing public choice in seventeenth-century England. In The Journal of Economic History, 49(4), 1989.

O'DONNELL, Guillermo. 1999. Polyarchies and the (Un)Rule of Law in Latin America. In MÉNDEZ, Juan E.; O’DONNELL, Guillermo and PINHEIRO, Paulo Sérgio. (eds.). The 
(Un)Rule of Law and the Underprivileged in Latin America. Notre Dame: University of Notre Dame Press, 1999.

PRZEWORSKI, Adam. Minimalist conception of democracy: a defense. In SHAPIRO, Ian and HACKER-CORDÓN, Casiano. (edit.). Democracy's Value. Cambridge: Cambridge University Press, 2011.

PRZEWORSKI, Adam, STOKES, Susan and MANIN, Bernard (eds.). Democracy, Accountability, and Representation. Cambridge: Cambridge University Press, 2012.

ROEMER, John E. Egalitarian Perspectives. Cambridge: Cambridge University Press, 1996.

ROEMER, John E. Theories of distributive justice. Cambridge: Harvard University Press, 1998.

ROSANVALLON, Pierre. Le sacre du citoyen. Histoire du suffrage universel en France. Paris: Gallimard, 1992.

ROUSSEAU, Jean-Jaques. Du contrat social, ou principes du droit politique. In Collection Complète des Oeuvres. Genève, 1780-1789, vol. 1, in-4º́ Édition en ligne www. rousseauonline.ch, version du 7 octobre 2012.

SCHAUER, Frederick. Playing by the Rules: a philosophical examination of rule-based decisionmaking in law and in life. Oxford: Clarendon Press, 2001.

SCHMITT, Carl. Teoría de la Constitución. Madrid Editorial Revista de Derecho Privado, 1970.

SCHUMPETER, Joseph A. Capitalism, Socialism and Democracy. New York: Taylor \& Francis, 2003. 